Multiple drug use in patients with comorbidity and multimorbidity: proposal for standard definitions beyond the term polypharmacy

Kadam UT ${ }^{1,4 *}$, Roberts $\mathrm{I}^{2}$, White $\mathrm{S}^{3}$, Bednall $\mathrm{R}^{2}$, Khunti $\mathrm{K}^{4}$, Nilsson $\mathrm{PM}^{5}$, Lawson $\mathrm{CA}^{4}$

${ }^{*}$ corresponding author

Umesh T. Kadam

Professor of Primary Care and Public Health Research

Diabetes Research Centre, Gwendolen Rd, Leicester, United Kingdom, LE5 4PW

utk2@leicester.ac.uk

1. Department of Health Sciences, University of Leicester, UK

2. University Hospitals of North Staffordshire, Staffordshire, UK

3. School of Pharmacy, Keele University, UK

4. Diabetes Research Centre, University of Leicester, UK

5. Department of Clinical Sciences, Lund University, Sweden

Keywords: diabetes; heart failure; breast cancer; polypharmacy; comorbidity; multimorbidity 


\begin{abstract}
With older and ageing populations, patients experience multiple chronic diseases at the same time. Individual chronic disease guidelines often recommend pharmacological therapies as a key intervention, resulting in patients being prescribed multiple regular medications for their different diseases. Whilst the term 'polypharmacy' has been applied to the use of multiple medications, there is no consistent definition and this term is now being used all inclusively. To improve both scientific rigor and optimal patient care, it is crucial that a standard terminology is used which reclassifies the term 'polypharmacy' into distinct phenotypes relating to the index chronic disease, additional conditions to the index ('comorbidity') or the experience of multiple chronic conditions at the same time (multimorbidity).
\end{abstract}

Using three exemplar index conditions; heart failure, type 2 diabetes and breast cancer, we propose the reclassification of the term 'polypharmacy' into three distinct phenotypes. First, index drug or multi-index drug therapy, where each index condition creates multiple drug use for that condition; second, co-drug therapy, where addition of other comorbid conditions increases the multiple drug use and may influence the management of the index disease and third, multi drug therapy, where adult population with multimorbidity may be on many drugs.

This paper reviews guidelines for the individual exemplars to develop the basis for the new terms and then develops the pharmaco-epidemiology of multiple drug use further by reviewing the evidence on the relationship between the phenotypic classification and important outcomes. The importance of standardising 'polypharmacy' terminology for the scientific agenda and clinical practice is that it relates to an index condition or disease safety outcomes including drug interactions, adverse side effects in hospital admissions and related 'polypill' concept. 


\section{What is new?}

The paper proposes alternative terminology for polypharmacy which links the use of multiple drugs to comorbidity and multimorbidity using three exemplars.

\section{What this adds to what is known?}

The term polypharmacy is applied to a variety of clinical scenarios and in particular to the use of multiple drugs in the same person. However it does not meet the scope nor scientific rigor needed for clinical practice or research.

\section{What is the implication?}

The benefits of the proposed more sensitive definition relate to scientific rigor to compare evidence using a more structured and standard definition and measure efficacy of outcomes following drug intervention models and better understanding of case mix when classifying diseases and drug treatments in populations.

\section{What should change now?}

The three distinct phenotypes proposed are (i) index drug or multi-index drug therapy, where each index condition creates multiple drug use for that condition; (ii) co-drug therapy, where addition of other comorbid conditions increases the multiple drug use and may influence the management of the index disease and (iii) multi drug therapy, where adult population with multimorbidity may be on many drugs. 


\section{Background}

Drugs play a key role in the routine management of chronic diseases including preventing progression and improving prognosis, management of physiological symptoms (e.g. pain) and improving mental health problems. ${ }^{1}$ Some of the many different examples include the endocrine system (e.g. diabetes) ${ }^{2}$, cardiovascular system (e.g. heart failure) ${ }^{3}$ and now increasingly cancer ${ }^{4}$ which, with improving prognosis, is also managed as a chronic longterm condition. The current evidence-based approach to clinical management has meant that multiple drug prescribing has been translated into routine clinical practice via national and local guidelines..$^{5,6,7}$

Individual chronic disease guidelines often include recommendations on different medications and the implementation of each guideline results in a patient with at least two or more drug classes, often initiated at the onset for treatment, control or the prevention of linked diseases. Yet, the individual patient experience is often of two or more chronic conditions at the same time, which is an issue not just for the old, but for the larger population experiencing chronic diseases. Therefore, people experiencing multiple diseases will have an escalating number of drugs for each individual condition. This phenomenon has been increasingly cited in literature ${ }^{8,9}$ and many studies have been incorporating the use of multiple drugs by patients under the umbrella term 'polypharmacy'. ${ }^{10,11}$ However, there are problems with this approach as the term 'polypharmacy' has varied meanings, which include the number of drugs, any medications associated with ageing or the adverse events for multiple drug combinations. ${ }^{12}$ For example, in a systematic review, over $80 \%$ of studies had used different numerical values to define polypharmacy and the remainder had used alternative definitions relating to the care context or other descriptive statements. ${ }^{13}$ The term 'polypharmacy' in practice and research has come to be an inclusive generic term for any type of terminology, which reduces the ability to observe more complex relationships between specific drug combinations and outcomes ${ }^{14}$ or to compare studies which have used different criteria and definitions. The other key scientific gap is the lack of any clear 
definitions which link the specific combination of multiple chronic diseases to the prescribing or use of multiple drugs. This link is crucial as the status of the chronic disease and the use of drugs as an intervention, are implicitly linked to evidence for future clinical and healthcare outcomes.

In scientific literature, people who experience multiple chronic diseases have been defined into the distinct but related concepts of comorbidity or multimorbidity. Comorbidity is defined as the study of a primary index disease in the context of the other diseases, or as the consequence, but multimorbidity is defined as the experience of two or more chronic diseases by an individual. ${ }^{15}$ Despite clear epidemiological and increasingly clinical approaches to the experience of multiple conditions, no such definitions have been applied to multiple drug use in an individual, nor how multiple drugs might link to the disease status. There is a clear necessity that the experience of multiple chronic conditions and the associated scale of drug use in the larger population require standard definitions. The term 'polypharmacy' fails to meet the scope of this topic and this umbrella term needs to distinguish between disease indications for drug treatment and 'polypharmacy' in older populations.

In the following sections, three empirical examples of type 2 diabetes, heart failure and breast cancer are used to delineate the concepts by using the current evidence-based guidelines and the implications of multiple drug use for each condition are drawn out. A case with all three conditions is then used to illustrate the links between disease, multiple diseases and multiple drug use, concluding with a proposal for standard definitions and epidemiological approaches to multiple drug use in adult populations (Table 1).

\section{Chronic disease guidelines and drug recommendations}

1. Type 2 diabetes mellitus 
Clinical context - In patients with established type 2 diabetes mellitus, patients will often start with a Biguanide (e.g. Metformin) but alternative will include Sulphonylurea (e.g.

Gliclazide).2,5 If the patient remains poorly controlled, then there may either be the addition of insulin or other oral anti-diabetic drugs. In terms of prevention approaches, other adjunct drugs that may be rapidly initiated are aimed at the reduction of cardiovascular outcomes, and renal or ocular complications. In patients with type 2 diabetes, at the age of 45 years, it is estimated that around $40 \%$ have hypertension and by the age of 75 years around $60 \%$ have hypertension or comorbid cardiovascular and renal complications..$^{16,17}$ So the potential range of other drug classes that could be used in patients with type 2 diabetes include antihypertensives, the specific use of ACE (Angiotensin Converting Enzyme) inhibitors or statins for lipid lowering.

Epidemiological definitions - The index disease status in this example is type 2 diabetes mellitus type 2. The other comorbid diseases in this population may include complications such as hypertension and cardiovascular disease which require drug treatment or other conditions that may influence the index condition, for example, depression. ${ }^{18}$

Pharmaco-epidemiology definitions - The drugs that are initiated are usually dependent on the severity of presentation, but the index drug therapy for type 2 diabetes mellitus is most often a Biguanide (i.e. Metformin). The requirement for optimal diabetic control may require the addition of other anti-diabetic drugs, such as other oral hypoglycaemics or insulin i.e.

multi-index therapies. The co-drug therapy in diabetic population may include antihypertensives (i.e. ACE inhibitors), lipid lowering drugs, and specific drugs indicated for other chronic diseases that impact on the type 2 diabetes. However, there may also be codrug therapy that potentially negatively impacts the index disease under this definition too e.g. steroids in diabetes. ${ }^{19}$

2. Heart failure with left ventricular systolic dysfunction (LVSD) 
Clinical context - There are a range of CVD drugs used in HF with LVSD, with some that are recommended in all patients and others that are indicated and used depending on the clinical severity and comorbidity. Common comorbidity in HF populations includes hypertension (73\%), chronic obstructive pulmonary disease (31\%) and chronic kidney disease (46\%). ${ }^{20}$ Using the American and European national guidance for $\mathrm{HF}^{6,21}$, there are five CVD drug groups that might be prescribed for HF. Current evidence recommends that both ACEi and Beta-receptor blockers are prescribed as first line treatment for all patients with LVSD who do not have other clinical contra-indications. The other four drug groups depending on the clinical context and severity include: (i) aldosterone antagonists, (ii) angiotensin-2 receptor antagonists, (iii) vasodilators such as hydralazine and nitrates and (iv) digoxin. In addition, diuretics are used in all patients as required depending on clinical indication.

Epidemiological definitions - The index disease status in this example is heart failure with LVSD. The other comorbid diseases in this population may include conditions such as atrial fibrillation and ischaemic heart disease which require specific drug treatments or other conditions that may influence the index condition.

Pharmaco-epidemiology definitions - The drugs that are initiated are usually dependent on the severity of presentation, but the index drug therapies for heart failure with LVSD are usually an Angiotensin Converting Inhibitor (e.g. Ramipril) and cardio-selective beta-receptor blocker (e.g. Bisoprolol). The requirement for effective symptom control may require the addition of other drugs, such as angiotensin-2 receptor antagonists (ARBs) or diuretics i.e. multi-index drug therapies. The co-drug therapy in heart failure with LVSD population may include anti-hypertensives (e.g. Amlodipine), statins and anti-coagulants, and specific drugs indicated for other chronic conditions that influence the heart failure status adversely e.g. anti-depressants. ${ }^{22}$

3. The example of breast cancer 
Context - There is increasing interest in how the comorbidity status for cancer patients influences outcomes. Examples of common comorbidity in the breast cancer population aged 75 years and over include cardiovascular disease (55\%), hypertension (32\%), diabetes (32\%), COPD (10\%), and dementia (7\%). ${ }^{23,24}$ Whilst such evidence is beginning to accrue, the current approaches to treatment are mainly dependent on the type and stage of breast cancer. Yet, there is an absolute necessity for standard definitions as multiple drug treatments in breast cancer change and on-going treatment creates issues of comorbid disease complications and surveillance safety.

This example provides the ultimate challenge to the pharmaco-epidemiology phenotype definition as treatment options are wide-ranging and change over time for the acute and chronic phases. Drugs used in breast cancer now include specific targets (e.g. receptor status determined by genetic risk) with some patients having multiple lines of sequential chemotherapies that may be as a short course or prolonged until there is disease progression. ${ }^{25,26}$ Current drug classes cover: (i) combination chemotherapy, (ii) hormone therapy or (iii) targeted biological therapy, each with their own sub-classes. The drug treatment covers initial therapy and the long-term therapy usually through use of hormone drug regimens, as the effectiveness of treatment has led to becoming a chronic 'disease' state with increased or normal survival times.

At initiation of treatment, the one chemotherapy agent considered as an option in absence of contraindication, in all breast cancer patients is an anthracycline, often in the form of Epirubicin (in NICE UK guideline). ${ }^{27}$ Other initiating therapies can be tailored to the stage and include E-CMF - epirubicin, cyclophosphamide, methotrexate and fluorouracil) or FEC (fluorouracil, epirubicin, cyclophosphamide). Another drug class that most patients will have in their chemotherapy is taxanes such as docetaxel or paclitaxel. ${ }^{28}$ When and how they are given will depend on the individual patient, e.g. nodal involvement will have docetaxel as part of their adjuvant treatment; paclitaxel tends to be given in metastatic disease; whereas triple receptor negative patients may have carboplatin before any taxane is used. 
Some patients may have multiple lines of sequential chemotherapy, such as a short course of taxanes or prolonged treatment until disease progression or toxicities emerge. For metastatic disease, additional interventions include monoclonal agents such as trastuzumab or emtansine. ${ }^{29}$ Often when deciding on the next line of therapy, pre-existing toxicities from previous lines of chemotherapies, as well as their co-morbidities and drug history are accounted for in the decision-making process.

The breast cancer example illustrates the direct issues between the concepts of comorbidity and multiple drug therapy. Pre-cancer comorbidity influences treatment options as well as the cancer drug treatment subsequently influencing the emergence of other complicating comorbidities. For example, anthracyclines, trastuzumab and taxanes are responsible for some of the acute and long term cardiotoxicities, in particular heart failure, and other complications such as liver and renal disease. ${ }^{30}$ Other toxicities include bevacizumab which influences hypertension and capecitabine which is being investigated in triple negative cancers $^{31}$, as an alternative or in addition to standard chemotherapy which influences angina. ${ }^{32}$

In terms of potential co-drug therapies, these include hormonal treatments such as tamoxifen or anastrozole. ${ }^{33}$ These breast cancer treatments on their own create conflict issues with other co-drug therapies such as antidepressants, warfarin or allopurinol. ${ }^{34,35}$

Epidemiological definitions - The index status in this example is breast cancer. The other comorbid diseases in this population may include conditions related to drug treatments such as heart, liver or renal disease or conditions which affect the index cancer.

Pharmaco-epidemiology definitions - The drugs that are initiated are usually dependent on the stage of breast cancer, and usually there are multi-index drug therapies which are combination of up to several chemotherapies (e.g. epirubicin, cyclophosphamide, methotrexate and fluorouracil or cyclophosphamide, epirubicin and fluorouracil). The requirement for effective symptom control may result in a rapid prescribing cascade, so the 
co-drug therapy in breast cancer population may include symptomatic control (for example, anti-emetics, corticosteroids, iron), as well as specific drugs for other chronic diseases that influence the onset or progression of the cancer or are a consequence of the cancer. ${ }^{36}$ However, here there is an additional distinct concept for defining the use of multiple drugs, which is the distinction between the acute phase treatment and the longer-term chronic treatment in the breast cancer remission state. In the breast cancer example, index multidrug therapies will be used, but in the longer-term treatment an index follow-up therapy, such as Tamoxifen will be used. ${ }^{37}$ The cancer example is in contrast to the other diabetes and heart failure example, where drugs once added usually result in a lifelong use and are rarely stopped only because of side effects. In breast cancer 'chronic disease' scenario there are distinct and different phases of drug treatment, which balance between the acute proactive drug treatments compared to the potential longer-term preventative treatment.

\section{A multimorbid patient with type 2 diabetes, LVSD heart failure and breast cancer}

If a patient were to have all three conditions at the same time, the utility of the terminology is further strengthened (Figure 1). The index multi-drug and co-drug would combine together to create a separate phenotype which is multi-drug therapy. The multi-drug therapy definition would then apply to the combination of any index and co-drug therapies and any additional drugs prescribed for specified diseases or conditions. The term does not need to be referenced necessarily to any index condition so that the focus is on the patient taking all their drugs. In the above sections the focus was on conditions related to index or comorbidity, especially when influences the treatment and outcomes of an index condition. However as the patient and populations age, other drugs will be added for other conditions, which means that multi-drug therapy is the summation of all potential treatments.

A further point is the way in which multi-drug therapy occurs. For chronic conditions like diabetes and heart failure there may be gradual increase in number of drugs but in cancer, the prescribing cascade may be rapidly turn into multi-drug-therapy. For conditions such as cancer and heart failure, and additional feature may be the initiation of the frailty state ${ }^{38}$ 
which may further increase drug treatments, and the combination of disease and frailty is further associated with adverse outcomes.

\section{Setting pharmaco-epidemiology phenotypes within current evidence on outcomes}

The following sections will illustrate how the epidemiological definitions, as applied to the three exemplar conditions, are associated with outcomes. This alignment of phenotypes to outcomes under-pins the rationale for the proposed pharmaco-epidemiology phenotypes and the importance of a more sensitive definition to describe the prescription of multiple drugs used by patients. Using the proposed definitions, index therapy outcomes relate to improving the prognosis of the index disease; co-drug therapy outcomes relate to improvement or worsening of the index disease as well as interactions between the index drug and co-drug therapies. Finally, multi-drug therapy outcomes focus on patient centred outcomes and health prioritisation.

Index drug therapy outcomes

For type 2 diabetes, the key initiating drug is often Metformin ${ }^{39,40}$ and evidence has shown that it is associated with improved diabetes outcomes and cardiovascular outcomes. ${ }^{41}$ Whilst there are other oral hypoglycaemics (sulphonylurea or SGLT2 inhibitors) that may be added to improve control, Metformin is still the main indicative drug for T2D. There is evidence that adding sulphonylyurea ${ }^{42}$ or insulin ${ }^{43}$ improves diabetes control but not necessarily the outcomes over long-term. Evidence on the long-term benefits of other drug classes, such as glitazones ${ }^{44}$ and new SGLT2 inhibitors, ${ }^{45,46}$ is just emerging and Metformin still remains the first line treatment in current clinical practice.

For heart failure with LVSD, the key initiating drug treatment is with multi-index drug therapies of Angiotensin Converting Enzyme (ACEi) and beta-receptor blockers. ${ }^{47}$ Angiotensin-converting-enzyme (ACE) inhibition reduces overall mortality by 16 to $40 \%$, reduces hospitalisations for asymptomatic HF patients with reduced ejection fraction ${ }^{48}$ and 
improves quality of life. ${ }^{49}$ The use of beta-blocker therapy, once considered counterintuitive, is now a standard guideline recommendation, with evidence of a mortality benefit. ${ }^{50}$

The evidence on breast cancer combination drug approaches is complex, with no single drug or combinations being the preferred approach, which is dependent on the type of tumour, extent of metastases and whether it is receptor sensitive. ${ }^{51,52}$ The same chemotherapies are also used for other types of cancers, so here the value of terminology relates to logging the primary treatment in medication history with diagnosis.

\section{Co-drug therapy outcomes}

The purpose of the co-drug therapy definition is that it provides the standard terminology for common drug treatments that impact on the management or prognosis of an index disease. So, for T2D, common co-drug therapies such as anti-hypertensives and statins are important in the prevention of the clinical sequelae of T2D. ${ }^{53,54}$ In addition to the beneficial and possible synergistic effects of index and co-drug therapies for improving disease outcomes, other codrug therapies may have antagonistic or harmful effects on the index condition or its management. Examples in T2D are the hyperglycaemic effects of corticosteroids ${ }^{55}$ or the severe and prolonged hypoglycemic effects of some lipid lowering agents e.g gemfibrozil, which interfere with the metabolism of some short-acting secretagogues e.g. repaglimide. ${ }^{56}$ Conversely over-treatment of the index type 2 diabetes mellitus may also lead to adverse outcomes as in the case of heart failure and mortality outcomes. ${ }^{57}$

For HF with LVSD, common co-therapy drugs that might have a beneficial effect on HF outcomes include anticoagulants such as warfarin ${ }^{58}$ or anti-arrhythmics such as Amiodarone, both prescribed for AF comorbidity. ${ }^{59}$ However, other co-drug therapies regularly prescribed for other concomitant conditions can have an antagonistic effect on index drug therapies. Clear examples include the sodium and fluid retention and increased systemic vascular resistance associated with nonsteroidal anti-inflammatory drugs (e.g. Diclofenac, lbuprofen) 
and the pro-arrhythmic effects of antidepressants such as amitriptyline. ${ }^{60,61}$ Heart failure is also commonly associated with frailty, and this may also affect the cardiovascular outcomes. ${ }^{62}$

For breast cancer, other co-drug therapies could include symptomatic control of pain or nausea $^{63,64}$, as well as treatment of any complications. However, cancer patients are particularly susceptible to drug interactions particularly in the presence of malnutrition and renal or hepatic dysfunction. A common example of adverse co-therapy is in the increased risk of bleeding from Warfarin in the presence of anti-neoplastic agents. ${ }^{65}$

All three chronic conditions have a higher risk of co-morbid depression which influences selfcare management of the index condition and means that anti-depressants often feature as a long-term co-drug therapy. ${ }^{66}$

\section{Multi-drug therapy outcomes}

The above sections show how a patient experiencing just these 3 conditions will quickly arrive at a multi-drug state. The implicit drivers for this phenotype is the single disease guidelines which promote the use of the individual index drugs or co-drug combinations to improve outcomes but also potentially influence adverse outcomes. In ageing populations the number of diseases and associated multi-drug therapies increase with a reported $20 \%$ of adults older than 65 years prescribed 10 or more medications. ${ }^{67}$ Whilst each individual set of multi-index and co-drug therapies have specific benefits, the culmination of such multi-drug therapies is associated with adverse outcomes including quality of life, disability, hospital admissions and mortality. ${ }^{68-70}$ Whilst any drugs without clear indication should be removed, prioritisation of remaining disease indicated drug therapies should take account of patient preferences for health goals. ${ }^{71}$ 


\section{Discussion}

Using the three case examples of chronic illness which includes the novel implications of cancer, our paper proposes and provides the definitions for multiple drug use in patients with multiple chronic illnesses and diseases. It links the use of multiple drug use to the specific terms of comorbidity and multimorbidity, and provides the distinct scope of terminology which is currently not specifically embraced by the term 'polypharmacy'. The terms it proposes are index drug therapy or multi-index therapies (and index follow-on therapy as in the specific case of cancer), co-drug therapies, multi-drug therapies and total drug therapy. The importance of clear and standard terminology relates to the chronic disease model ${ }^{72}$ in which the goal is on improvement of the clinical outcomes or patient-reported outcomes. Whilst, drug treatments are one key component of the multi-faceted interventions which include non-drug therapies, the sole aim and purpose of multiple drug use is to maximise the patient and population benefit and gain the best outcomes.

By proposing clear definitions and terminology and application to the index disease status, comorbidity or multimorbidity, a consistent approach to the clinical and research management can be developed. The benefits of the terminology will be helping clinicians to review potentially harmful multiple drugs by being able to structure them using an organising principle e.g. a HF specialist might start with the adverse co-therapy drugs whereas a gerontologist for a frail patient might start on any drugs that don't influence patient important outcomes. The downfall of a vague definition such as 'polypharmacy' and benefits of the proposed more sensitive definition are potentially in terms of (i) de-prescribing - clinicians can perform drug reviews using an organising principle. ${ }^{73}$ This might be looking first at any non-indicated drug therapies followed by harmful co-therapy drugs when managing the index disease, or at patient priorities when managing older frail patients with multi-drug therapy when drug-drug interactions are common, ${ }^{74}$ (ii) scientific rigor - the ability to compare evidence using a more structured and standard definition and measure efficacy of outcomes following drug intervention models and (iii) public health - better understanding of case mix when classifying diseases and drug treatments in populations. Overall the key strength of 
the new classification is that it enables alignment of conditions with drug interventions, outcomes and patient priorities.

These definitions also potentially underpin the key scientific concept of the 'polypill'75 and the drug typology of interactions, safety and side effects. Conceptualising the 'polypill' as index drug therapies or co-drug therapies provides the framework by which dimensions of disease and drugs could be included. Whilst the 'polypill' concept uses multiple drug combinations as a potential benefit to patients and populations, the converse problem is that the multimorbidity creates drug-drug interactions and inappropriate prescribing in older populations. ${ }^{76}$ Review of current guidelines shows that drug-drug interactions are common and associated with hospitalisation, which further supports the characterisation of the multidrug phenotype to identify the level and grade of such interactions. ${ }^{77-79}$ Other studies have also shown the potential effect on quality of life and patient safety in older populations. ${ }^{80-83} \mathrm{~A}$ recent study on patient safety has suggested there are over 200 medication errors per year in the UK and adverse drug reactions associated with these could account for several thousand deaths per year. ${ }^{84}$ The term 'polypharmacy' implicitly covers the implications for the patient and population in which drug interventions are a key part of disease prevention and chronic disease management model. It may be assumed by society and by clinical guidelines that polypharmacy is a good thing but really, we don't know that to be the case and won't do until there's good evidence of how multiple drug use for specific indications is linked with patient outcomes.

The paper illustrates through the index case examples, how multiple drug use originates when each disease treatment model is applied and how that use translates into use of multiple drugs in an individual patient who has, for example, type 2 diabetes, heart failure and cancer together at the same time. This creates an imperative that standard terminology is employed when trying to understand this field for clinical and research purposes. Arguably, there may be a view that different terminology may be over-elaborating the term 'polypharmacy'. Conversely, the alternative and clear view proposed in the paper is that it is 
vitally important to understand the underlying origins of multiple drug use which links single disease drug treatment to multiple disease drug treatment and how that relates to clinical, healthcare, safety or patient outcomes.

In conclusion, using three different chronic disease examples, our paper proposes the replacement of the term 'polypharmacy'. By linking an index condition with the associated multi-index drug use, to the associated comorbidity conditions with related co-drug use to all other non-related disease indicated drugs, provides the basis of clearer understanding of the older person with multimorbidity who has overall 'polypharmacy'. The importance of providing a clear phenotype classification for 'polypharmacy' enables the key link to the potential mechanisms, such as drug interaction and safety that ultimately relates to the improvement of clinical and healthcare outcomes in chronic disease management.

\section{Acknowledgements}

CAL is supported by the University of Leicester Wellcome Trust Institutional Strategic Support Fund. 
Table 1: Linking disease status to drug phenotypes

\begin{tabular}{|c|c|c|c|}
\hline Disease definitions & Disease status & Drug phenotypes & Indicator drugs \\
\hline Index disease & diabetes mellitus type 2 & $\begin{array}{l}\text { Index drug therapy } \\
\text { Index multi-drug therapy }\end{array}$ & $\begin{array}{l}\text { biguanide } \\
\text { biguanide, sulphonylurea } \\
\text { or insulin }\end{array}$ \\
\hline Comorbidity & $\begin{array}{l}\text { hypertension, } \\
\text { cardiovascular disease }\end{array}$ & Co-drug therapy & $\begin{array}{l}\text { anti-hypertensives } \\
\text { (specifically ACEi), lipid } \\
\text { lowering drugs, other } \\
\text { chronic diseases }\end{array}$ \\
\hline Multimorbidity & $\begin{array}{l}\text { diabetes mellitus, } \\
\text { hypertension, chronic } \\
\text { kidney disease, plus } \\
\text { other chronic conditions }\end{array}$ & Multi-drug therapy & $\begin{array}{l}\text { biguanide, sulphonylurea, } \\
\text { insulin, anti- } \\
\text { hypertensives, lipid } \\
\text { lowering drugs }\end{array}$ \\
\hline \multirow[t]{2}{*}{ Index disease } & \multirow[t]{2}{*}{ heart failure with LVSD } & Index drug therapy & ACEi and Beta-blocker \\
\hline & & Index multi-drug therapy & $\begin{array}{l}\text { ARB, Aldosterone } \\
\text { Antagonists, Digoxin, } \\
\text { Hydralazine/Nitrate } \\
\text { Diuretics }\end{array}$ \\
\hline Comorbidity & $\begin{array}{l}\text { atrial fibrillation, } \\
\text { ischaemic heart disease }\end{array}$ & Co-drug therapy & $\begin{array}{l}\text { nitrates, anti-coagulants, } \\
\text { aspirin, statins, } \\
\text { amlodipine, amioderone, } \\
\text { digoxin }\end{array}$ \\
\hline Multimorbidity & $\begin{array}{l}\text { heart failure, } \\
\text { hypertension, chronic } \\
\text { kidney disease }\end{array}$ & Multi-drug therapy & $\begin{array}{l}\text { ACEi, beta-blockers, } \\
\text { diuretics, nitrates, digoxin } \\
\text { and other drugs }\end{array}$ \\
\hline \multirow[t]{2}{*}{ Index disease } & \multirow[t]{2}{*}{ breast cancer } & Index drug therapy & chemotherapy \\
\hline & & $\begin{array}{l}\text { Index disease multi-drug } \\
\text { therapies }\end{array}$ & $\begin{array}{l}\text { combination } \\
\text { chemotherapy }\end{array}$ \\
\hline Comorbidity & organ involvement & Co-drug therapies & $\begin{array}{l}\text { anti-emetics, } \\
\text { corticosteroids, iron }\end{array}$ \\
\hline Multimorbidity & $\begin{array}{l}\text { breast cancer, } \\
\text { cardiovascular, renal or } \\
\text { bone disease } \\
\text { complications }\end{array}$ & Multi-drug therapies & $\begin{array}{l}\text { cancer, symptom, chronic } \\
\text { disease, anti-depressants }\end{array}$ \\
\hline Index chronic disease & $\begin{array}{l}\text { breast cancer in } \\
\text { remission }\end{array}$ & Index follow-up therapy & tamoxifen \\
\hline
\end{tabular}

${ }^{*}$ An additional term not linked to any condition but all the drugs that a patient uses is total drug therapy 
Figure 1: Conceptual diagram for definitions

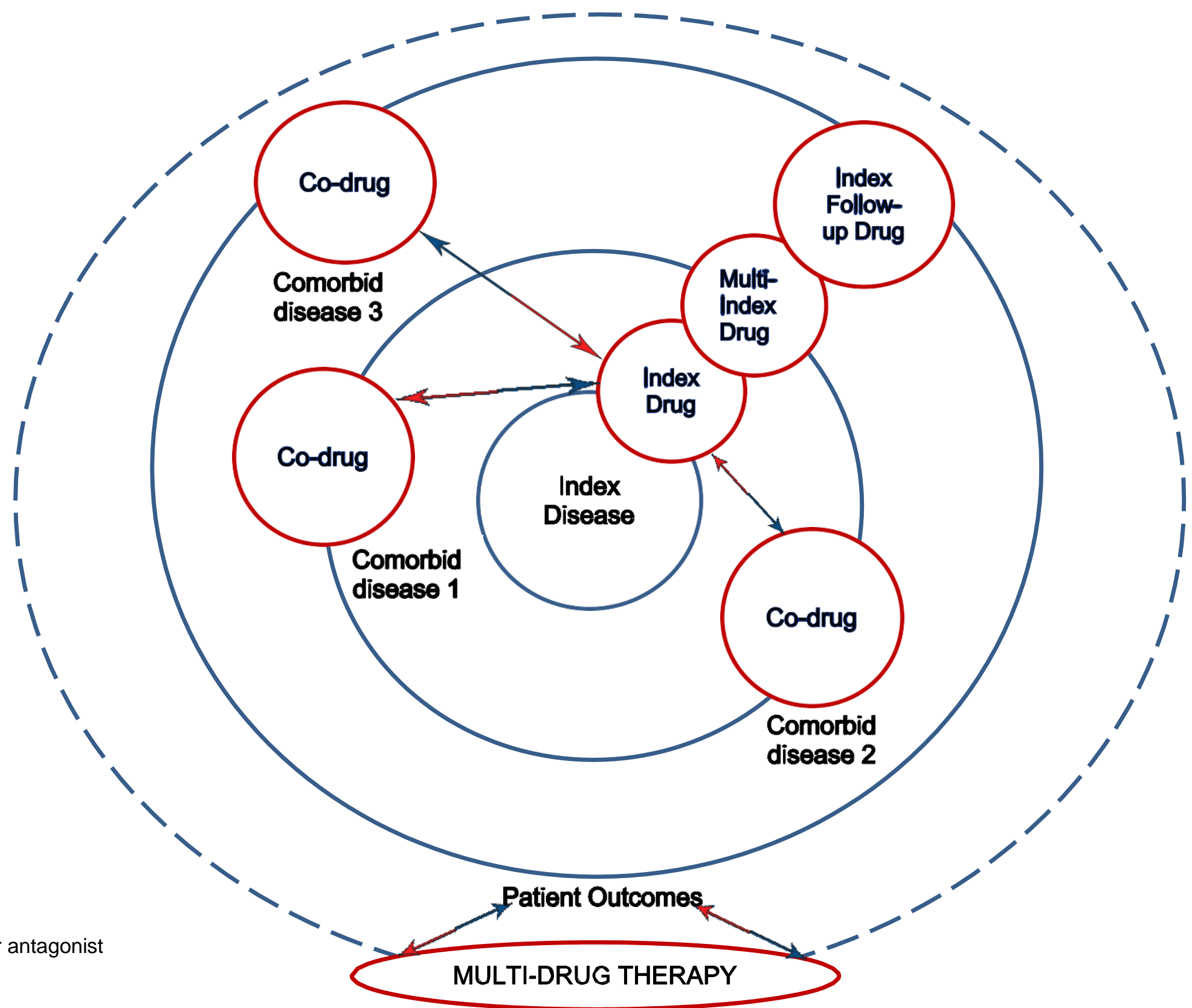


2 1. Doos L, Roberts EO, Corp N, Kadam UT. Multi-drug therapy in chronic condition

3 multimorbidity: a systematic review. Fam Pract 2014;31(6):654-63.

4 2. Inzucchi SE, Bergenstal RM, Buse JB, Diamant M, Ferrannini E, Nauck M et al.

5 Management of Hyperglycemia in Type 2 Diabetes, 2015: A Patient-Centered Approach:

6 Update to a Position Statement of the American Diabetes Association and the European

7 Association for the Study of Diabetes. Diabetes Care 2015;38(1):140-149.

8 3. Antman EM, Bax J, Chazal RA, Creager MA, Filippatos G, Halperin JL et al. Updated

9 Clinical Practice Guidelines on Heart Failure: An International Alignment. Circulation 10 2016;134:e280-e281.

11 4. Gradishar W, Salerno KE. NCCN Guidelines Update: Breast Cancer. J Natl Compr Canc 12 Netw 2016;14(5 Suppl):641-4.

13 5. American Diabetes Association. Approaches to glycemic treatment. Sec. 7. In Standards 14 of Medical Care in Diabetes 2016. Diabetes Care 2016;39(Suppl. 1):S52-S59.

15 6. National Clinical Guideline Centre. (2010) Chronic heart failure: the management of 16 chronic heart failure in adults in primary and secondary care. London: National Clinical 17 Guideline Centre. Available from: http://guidance.nice.org.uk/CG108/Guidance/pdf/English.

18 7. Cardoso F, Costa A, Senkus E, Aapro M, André F, Barrios CH et al. 3rd ESO-ESMO 19 International Consensus Guidelines for Advanced Breast Cancer (ABC 3). Ann Oncol $20 \quad 2017 ; 28(12): 3111$.

21 8. Mannucci PM, Nobili A; REPOSI Investigators. Multimorbidity and polypharmacy in the 22 elderly: lessons from REPOSI. Intern Emerg Med 2014;9(7):723-34.

239 . Wehling M. Guideline-driven polypharmacy in elderly, multimorbid patients is basically 24 flawed: there are almost no guidelines for these patients. J Am Geriatr Soc 2011;59(2):376257.

26 10. Fulton MM, Allen ER. Polypharmacy in the elderly: a literature review. J Am Acad Nurse 27 Pract 2005;17:123-32.

28 11. Masnoon N, Shakib S, Kalisch-Ellett L, Caughey GE. What is polypharmacy? A 29 systematic review of definitions. BMC Geriatrics 2017;17:230.

30 12. Bushardt RL, Massey EB, Simpson TW, Ariail JC, Simpson KN. Polypharmacy: 31 Misleading, but manageable. Clin Interven Aging 2008;3(2):383-389. 
1 13. Masnoon N, Shakib S, Kalisch-Ellett L, Caughey GE. What is polypharmacy? A

2 systematic review of definitions. BMC Geriatr 2017;17(1):230.

3 14. Viktil KK, Blix HS, Moger TA, Reikvam A. Polypharmacy as commonly defined is

4 an indicator of limited value in the assessment of drug-related problems. $\mathrm{Br} \mathrm{J}$

5 Clin Pharmacol 2007;63(2):187-95.

6 15. van den Akker M, Buntinx F, Knottnerus JA. Comorbidity or multimorbidity: what's in a 7 name? A review of literature. Eur J Gen Pract 1996;2:65-70.

8 16. Piette JD, Kerr EA. The Impact of Comorbid Chronic Conditions on Diabetes Care.

9 Diabetes Care 2006;29(3):725-731.

10 17. Halter JB, Musi N, Horne FM, Crandall JP, Goldberg A, Harkless L et al. Diabetes and 11 Cardiovascular Disease in Older Adults: Current Status and Future Directions. Diabetes 12 2014;63(8):2578-2589.

13 18. Kadam UT, Jordan K, Croft PR. Clinical comorbidity was specific to disease pathology, 14 psychologic distress, and somatic symptom amplification. J Clin Epidemiol 2005;58(9):9091517.

16 19. Suissa S, Kezouh A, Ernst P. Inhaled corticosteroids and the risks of diabetes onset and 17 progression. Am J Med 2010;123(11):1001-6.

18 20. van Deursen VM, Urso R, Laroche C, Damman K, Dahlström U, Tavazzi L et al. Co19 morbidities in patients with heart failure: an analysis of the European Heart Failure Pilot 20 Survey. Eur J Heart Fail 2014;16(1):103-11.

21 21. Heart Failure Society of America, Lindenfeld J, Albert NM, Boehmer JP, Collins SP, 22 Ezekowitz JA et al. Comprehensive Heart Failure Practice Guideline. J Card Fail 23 2010;16(6):e1-194.

24 22. Brouwers C, Christensen SB, Damen NL, Denollet J, Torp-Pedersen C, Gislason GH et 25 al. Antidepressant use and risk for mortality in 121,252 heart failure patients with or without a 26 diagnosis of clinical depression. Int J Cardiol 2016;203:867-73.

27 23. Yancik R, Wesley MN, Ries LAG, Havlik RJ, Edwards BK, Yates JW. Effect of Age and 28 Comorbidity in Postmenopausal Breast Cancer Patients Aged 55 Years and Older. JAMA $292001 ; 285(7): 885-892$. 
24. Fu MR, Axelrod D, Guth AA, Cleland CM, Ryan CE, Weaver KR et al. Comorbidities and

2 Quality of Life among Breast Cancer Survivors: A Prospective Study. J Pers Med

3 2015;5(3):229-242.

4 25. Bastiaannet E, Charman J, Johannesen TB, Schrodi S, Siesling S, van Eycken L et al. A

5 European, Observational Study of Endocrine Therapy Administration in Patients With an

6 Initial Diagnosis of Hormone Receptor-Positive Advanced Breast Cancer. Clin Breast Cancer

7 2017; pii: S1526-8209(17)30728-0.

8 26. LeVasseur N, Chia SK. Sequential versus concurrent chemotherapy for adjuvant breast cancer: does dose intensity matter? Br J Cancer 2017;117(2):157-300.

11 and treatment. Clinical guideline [CG81] Published date: February 2009 Last updated:

12 August 2017. London: NICE. Available from: https://www.nice.org.uk/guidance/cg81.

13 28. Biganzoli L, Aapro M, Loibl S, Wildiers H, Brain E. Taxanes in the treatment of breast 14 cancer: Have we better defined their role in older patients? A position paper from a SIOG 15 Task Force. Cancer Treat Rev 2016;43:19-26.

16 29. Yan H, Yu K, Zhang K, Liu L, Li Y. Efficacy and safety of trastuzumab emtansine (T17 DM1) in the treatment of HER2-positive metastatic breast cancer (MBC): a meta-analysis of 18 randomized controlled trial. Oncotarget 2017;8(60):102458-467.

19 30. Guo S, Wong S. Cardiovascular toxicities from systemic breast cancer therapy. Front 20 Oncol 2014;4:1-10. doi: 10.1159/000357136.

21 31. Sharma P, López-Tarruella S, García-Saenz JA, Ward C, Connor CS, Gómez HL et al. 22 Efficacy of Neoadjuvant Carboplatin plus Docetaxel in Triple-Negative Breast Cancer:

23 Combined Analysis of Two Cohorts. Clin Cancer Res 2017;23(3):649-657.

24 32. Wittayanukorn S, Qian J, Johnson BS, Hansen RA. Cardiotoxicity in targeted therapy for 25 breast cancer: A study of the FDA adverse event reporting system (FAERS). J Oncol Pharm 26 Pract 2017;23(2):93-102.

27 33. Masuda N, Sagara Y, Kinoshita T, Iwata H, Nakamura S, Yanagita Y et al. Neoadjuvant 28 anastrozole versus tamoxifen in patients receiving goserelin for premenopausal breast 29 cancer (STAGE): a double-blind, randomised phase 3 trial. Lancet Oncol 2012;13(4):345-52.

30 34. Beijnen JH, Schellens JH. Drug interactions in oncology. Lancet Oncol 2004;5(8):489-96. 
35. Lees J, Chan A. Polypharmacy in elderly patients with cancer: clinical implications and

2 management. Lancet Oncol 2011;12(13):1249-57.

3 36. Paque K, Elseviers M, Vander Stichele R, Pardon K, Hjermstad MJ, Kaasa S et al.

4 Changes in medication use in a cohort of patients with advanced cancer: The international

5 multicentre prospective European Palliative Care Cancer Symptom study. Palliat Med 2017;

6 Dec 1:269216317746843.

7 37. Dowsett $\mathrm{M}$, Cuzick J, Ingle J, Coates A, Forbes J, Bliss $\mathrm{J}$ et al. Meta-analysis of breast

8 cancer outcomes in adjuvant trials of aromatase inhibitors versus tamoxifen. J Clin Oncol

9 2010;28(3):509-18.

10 38. Muhlack DC, Hoppe LK, Stock C, Haefeli WE, Brenner H, Schöttker B. The associations 11 of geriatric syndromes and other patient characteristics with the current and future use of 12 potentially inappropriate medications in a large cohort study. Eur J Clin Pharmacol 2018; doi: 13 10.1007/s00228-018-2534-1. [Epub ahead of print]

14 39. Rojas LB, Gomes MB. Metformin: an old but still the best treatment for type 2 diabetes. 15 Diabetol Metab Syndr 2013;5:6.

16 40. Maruthur NM, Tseng E, Hutfless S, Wilson LM, Suarez-Cuervo C, Berger Z et al. 17 Diabetes Medications as Monotherapy or Metformin-Based Combination Therapy for Type 2 18 Diabetes: A Systematic Review and Meta-analysis. Ann Intern Med 2016;164(11):740-51.

19 41. No Authors listed. Effect of intensive blood-glucose control with metformin on 20 complications in overweight patients with type 2 diabetes (UKPDS 34). UK Prospective 21 Diabetes Study (UKPDS) Group. Lancet 1998;352(9131):854-65.

22 42. Hong J, Zhang Y, Lai S, Lv A, Su Q, Dong Y et al. Effects of metformin versus glipizide 23 on cardiovascular outcomes in patients with type 2 diabetes and coronary artery disease. 24 Diabetes Care 2013;36(5):1304-11.

25 43. Hemmingsen B, Christensen LL, Wetterslev J, Vaag A, Gluud C, Lund SS et al. 26 Comparison of metformin and insulin versus insulin alone for type 2 diabetes: systematic 27 review of randomised clinical trials with meta-analyses and trial sequential analyses. BMJ 28 2012;344:e1771.

29 44. Lincoff AM1, Wolski K, Nicholls SJ, Nissen SE. Pioglitazone and risk of cardiovascular 30 events in patients with type 2 diabetes mellitus: a meta-analysis of randomized trials. JAMA $31 \quad 2007 ; 298(10): 1180-8$. 
1 45. Miller BR, Nguyen H, Hu CJ-H, Lin C, Nguyen QT. New and Emerging Drugs and

2 Targets for Type 2 Diabetes: Reviewing the Evidence. Am Health Drug Benefits

3 2014;7(8):452-463.

4 46. Kosiborod M, Cavender MA, Fu AZ, Wilding JP, Khunti K, Holl RW et al. Lower Risk of 5 Heart Failure and Death in Patients Initiated on Sodium-Glucose Cotransporter-2 Inhibitors 6 Versus Other Glucose-Lowering Drugs: The CVD-REAL Study (Comparative Effectiveness 7 of Cardiovascular Outcomes in New Users of Sodium-Glucose Cotransporter-2 Inhibitors).

8 Circulation 2017;136(3):249-259.

9 47. Sacks CA, Jarcho JA, Curfman GD. Paradigm Shifts in Heart-Failure Therapy - A 10 Timeline. N Engl J Med 2014;371:989-991.

11 48. Cohn JN, Tognoni G. A randomized trial of the angiotensin-receptor blocker valsartan in 12 chronic heart failure. N Engl J Med 2001;345:1667-1675.

13 49. Beller B, Bulle T, Bourge RC, Colfer $H$, Fowles RE, Giles TD et al. Lisinopril versus 14 placebo in the treatment of heart failure: the Lisinopril Heart Failure Study Group. J Clin 15 Pharm 1995;35:673-80.

16 50. CIBIS II Investigators. The Cardiac Insufficiency Bisoprolol Study II (CIBIS-II): a 17 randomised trial. Lancet 1999;353:9-13.

51. Abe O, Abe R, Enomoto K, Kikuchi K, Koyama $\mathrm{H}$; Masuda $\mathrm{H}$ et al. Effects of 19 chemotherapy and hormonal therapy for early breast cancer on recurrence and 15-year 20 survival: an overview of the randomised trials. Lancet 2005;365(9472):1687-1717. cancer: an overview. BMC Med 2015;13:195.

53. Patel A; ADVANCE Collaborative Group, MacMahon S, Chalmers J, Neal B, Woodward 24 $M$ et al. Effects of a fixed combination of perindopril and indapamide on macrovascular and microvascular outcomes in patients with type 2 diabetes mellitus (the ADVANCE trial): a randomised controlled trial. Lancet 2007;370(9590):829-40.

27 54. Kaasenbrood L, Poulter NR, Sever PS, Colhoun HM, Livingstone SJ, Boekholdt SM et 28 al. Development and Validation of a Model to Predict Absolute Vascular Risk Reduction by 29 Moderate-Intensity Statin Therapy in Individual Patients With Type 2 Diabetes Mellitus. Circ 30 Cardiovasc Qual and Outcomes 2016;9:213-221. 
1 55. Vidler J, Rogers C, Yallop D, Devereux S, Wellving E, Stewart O et al. Outpatient

2 management of steroid-induced hyperglycaemia and steroid-induced diabetes in people with

3 lymphoproliferative disorders treated with intermittent high dose steroids. J Clin Transl

4 Endocrinol 2017;9:18-20. doi:10.1016/j.jcte.2017.06.003.

5 56. Niemi M, Backman JT, Neuvonen M, Neuvonen PJ. Effects of gemfibrozil, itraconazole, 6 and their combination on the pharmacokinetics and pharmacodynamics of repaglinide:

7 potentially hazardous interaction between gemfibrozil and repaglinide. Diabetologia 2003;46:

8 347-351.

9 57. Lawson CA, Jones PW, Teece L, Dunbar SB, Seferovic PM, Khunti K et al. Association 10 Between Type 2 Diabetes and All-Cause Hospitalization and Mortality in the UK General 11 Heart Failure Population: Stratification by Diabetic Glycemic Control and

12 Medication Intensification. JACC Heart Fail 2018;6(1):18-26.

13 58. Homma S, Thompson JLP, Qian M, Ye S, Di Tullio MR, Lip GYH et al. Quality of 14 Anticoagulation Control in Preventing Adverse Events in Heart Failure Patients in Sinus 15 Rhythm: A Warfarin Aspirin Reduced Cardiac Ejection Fraction Trial (WARCEF) 16 Substudy. Circ Heart Fail 2015;8(3):504-509.

59. Kawabata M, Hirao K, Hachiya H, Higuchi K, Tanaka Y, Yagishita A et al. Role of oral amiodarone in patients with atrial fibrillation and congestive heart failure. $\mathrm{J}$ Cardiol 2011;58(2):108-115.

60. Arfè A, Scotti L, Varas-Lorenzo C, Nicotra F, Zambon A, Kollhorst B et al. Non-steroidal anti-inflammatory drugs and risk of heart failure in four European countries: nested casecontrol study. BMJ 2016;354:i4857.

\section{Rustad JK, Stern TA, Hebert KA, Musselman DL. Diagnosis and Treatment of}

Depression in Patients With Congestive Heart Failure: A Review of the Literature. The Prim Care Companion CNS Disord 2013;15(4):PCC.13r01511.

62. Sanders NA, Supiano MA, Lewis EF, Liu J, Claggett B, Pfeffer MA et al. The frailty syndrome and outcomes in the TOPCAT trial. Eur J Heart Fail 2018; doi: 10.1002/ejhf.1308. 
1 64. Booth CM, Clemons M, Dranitsaris G, Joy A, Young S, Callaghan W et al.

2 Chemotherapy-induced nausea and vomiting in breast cancer patients: a prospective

3 observational study. J Support Oncol 2007;5(8):374-80.

4 65. Camidge R, Reigner B, Cassidy J, Grange S, Abt M, Weidekamm E, et al. Significant

5 effect of capecitabine on the pharmacokinetics and pharmacodynamics of warfarin in

71. Carroll C, Hassanin A. Polypharmacy in the Elderly-When Good Drugs Lead to Bad patients with cancer, J Clin Oncol 2005;23:4719-25

66. Roberts ER, Green D, Kadam UT. Chronic condition comorbidity and multidrug therapy in general practice populations: a cross-sectional linkage study. BMJ Open 2014;4(7):e005429.

67. Nobili A, Franchi C, Pasina L, Tettamanti M, Baviera M, Monesi L et al. Drug utilization and polypharmacy in an Italian elderly population: the EPIFARM-elderly project.

Pharmacoepidemiol Drug Saf. 2011 May;20(5):488-96.

68. Bonaga B, Sánchez-Jurado PM, Martínez-Reig M, Ariza G, Rodríguez-Mañas L, Gnjidic $D$ et al. Frailty, Polypharmacy, and Health Outcomes in Older Adults: The Frailty and Dependence in Albacete Study. J Am Med Dir Assoc 2018;19(1):46-52.

69. Franchi C, Marcucci M, Mannucci PM, Tettamanti M, Pasina L, Fortino I et al. Changes in clinical outcomes for community-dwelling older people exposed to incident chronic polypharmacy: a comparison between 2001 and 2009. Pharmacoepidemiol Drug Saf 2016;25(2):204-11.

70. Lu WH, Wen YW, Chen LK, Hsiao FY. Effect of polypharmacy, potentially inappropriate medications and anticholinergic burden on clinical outcomes: a retrospective cohort study. 
1 75. Huffman MD, Xavier D, Perel P. Uses of polypills for cardiovascular disease and

2 evidence to date. Lancet 2017;389(10073):1055-1065.

3 76. Novaes PH, da Cruz DT, Lucchetti ALG, Leite ICG, Lucchetti G. The "iatrogenic triad":

4 polypharmacy, drug-drug interactions, and potentially inappropriate medications in older

5 adults. Int J Clin Pharm 2017;39(4):818-25.

6 77. Fick DM, Cooper JW, Wade WE, Waller JL, Maclean JR, Beers MH. Updating the Beers 7 criteria for potentially inappropriate medication use in older adults: results of a US consensus 8 panel of experts. Arch Int Med 2003;163(22):2716-24.

9 78. Dumbreck S, Flynn A, Nairn M, Wilson M, Treweek S, Mercer SW et al. Drug-disease 10 and drug-drug interactions: systematic examination of recommendations in 12 UK national 11 clinical guidelines. BMJ 2015;350:h949.

79. Zheng WY, Richardson LC, Li L, Day RO, Westbrook JI, Baysari MT. Drug-drug interactions and their harmful effects in hospitalised patients: a systematic review and metaanalysis. Eur J Clin Pharmaco. 2017;doi: 10.1007/s00228-017-2357-5.

80. Strandell J, Bate A, Lindquist M, Edwards IR; Swedish, Finnish, Interaction X-referencing 16 Drug-drug Interaction Database (SFINX Group). Drug-drug interactions - a preventable patient safety issue? Br J Clin Pharmacol 2008;65(1):144-6.

81. Kadam UT. Potential health impacts of multiple drug prescribing for older people: a casecontrol study. Br J Gen Pract 2011;61(583):128-30.

82. Kojima G, Bell C, Tamura B, Inaba M, Lubimir K, Blanchette PL et al. Reducing Cost by Reducing Polypharmacy: The Polypharmacy Outcomes Project. J Am Med Dir Assoc 2012;13(9):818.e11-818.e15. doi:10.1016/j.jamda.2012.07.019 .

83. Field TS, Gurwitz JH, Avorn J, McCormick D, Jain S, Eckler M et al. Risk factors for 24 25 adverse drug events among nursing home residents. Arch Intern Med 2001;161(13):16291634.

26 84. Elliott R, Camacho E, Campbell F, Jankovic D, Martyn St James M, Kaltenthaler E et 27 al.. Prevalence and Economic Burden of Medication Errors in the NHS in England. Rapid 28 evidence synthesis and economic analysis of the prevalence and burden of medication error 29 in the UK. Policy Research Unit in Economic Evaluation of Health and Care Interventions. 30 Universities of Sheffield and York, 2018. 
Multiple drug use in patients with comorbidity and multimorbidity: re-conceptualising 'polypharmacy' phenotype for clinical practice and research

Kadam UT*, Roberts I, White S, Bednall R, Khunti K, Nilsson PM, Lawson CA

\section{Conflicts statement}

Umesh T. Kadam: None

Isabel Roberts: None declared

Simon White: None declared

Ruth Bednall: None declared

Kamlesh Khunti: KK has acted as a consultant and speaker for Novartis, Novo Nordisk, Sanofi-Aventis, Lilly and Merck Sharp \& Dohme. He has received grants in support of investigator and investigator-initiated trials from Novartis, Novo Nordisk, Sanofi-Aventis, Lilly, Pfizer, Boehringer Ingelheim and Merck Sharp \& Dohme.

Peter Nilsson: None declared

Claire A. Lawson: None declared 